\title{
Clumped isotope geochemistry of Fe- carbonates from the Gunflint Formation
}

\author{
E.A. Holme ${ }^{1 *}$, G.A. HeNKes ${ }^{1}$, E.T. RASUbURY ${ }^{1}$, P. \\ FrALICK $^{2}$, N.J. TOSCA ${ }^{3}$, \& J.A. HuROWITZ ${ }^{1}$
}

${ }^{1}$ Department of Geosciences, Stony Brook University, Stony Brook, NY, USA

${ }^{2}$ Department of Geology, Lakehead University, Thunder Bay, ON, Canada

${ }^{3}$ Department of Earth Sciences, University of Oxford, Oxford, United Kingdom

The 1.88 Ga Gunflint Formation contains depositional facies rich in primary siderite, primary to diagenetic ankerite, and diagenetic to metamorphic dolomite/calcite [1, 2]. The Gunflint is an ideal setting for development of analytical strategies that allow isotope measurements of primary Fe-carbonates to constrain Precambrian ocean chemistry. To this end, we conducted carbonate clumped isotope measurements on samples collected in Thunder Bay, Ontario. Because physical separation of carbonate phases in the samples is difficult due to the small scale of compostional variation, we used a modified acid digestion technique to target siderite. Several samples from unweathered core material display millimeter-scale bands dominated by $\sim 20 \mu \mathrm{m}$ Fe-carbonate microspar. Siderite isolated from these bands yields clumped isotope temperatures of $37-45^{\circ} \mathrm{C}$ and calculated water oxygen isotope values of -8 to $-6 \%$ (VSMOW). Though preliminary, this is consistent with previous estimates of seawater temperature from chert [3] and $\delta^{18} \mathrm{O}$ value from iron oxides [4]. New data from both siderite and whole carbonate measurements will be presented and reconciled with models of Gunflint ironstone diagenesis.

To test the fidelity of siderite clumped isotope measurements, we have performed a series of constant composition precipitation experiments [5] in an anaerobic glovebox. Initial experiments at $25^{\circ} \mathrm{C}$ yielded clumped isotope ratios consistent with previous temperature calibrations [6, 7]; precipitations at warmer temperatures are ongoing.

[1] Floran, R.J. \& Papike, J.J. (1978). J. Pet. 19.2: 215-288.

[2] Fralick, P.W., et al. (2017). Prec. Res. 290:126-146. [3]

J. Marin-Carbonne et al. (2014). Prec. Res. 247: 223-234.

[4] Galili, N. et al. (2019) Science 365.6452: 469-473. [5] Beck, R. et al. (2013). J. Crys. Growth 380: 187-196. [6] Fernandez, A. et al. (2014). GCA 126: 411-421. [7] Van Dijk, J. et al. (2019). GCA 254: 1-20. 